\title{
Disentangling the role of connectivity, environmental filtering, and spatial structure on metacommunity dynamics
}

\author{
C. Moritz, C. N. Meynard, V. Devictor, K. Guizien, C. Labrune, J.-M. Guarini and N. Mouquet \\ C. Moritz (c-m.moritz@laposte.net), K. Guizien, C. Labrune and J.-M. Guarini, UPMC, Univ. Paris 06, Observatoire Océanologique, \\ FR-66650, Banyuls/Mer, France, and CNRS, UMR 8222, LECOB, Observatoire Océanologique, FR-66650, Banyuls/Mer, France. \\ Present address for CM: Inst. des Sciences de la Mer, Univ. du Québec à Rimouski, Rimouski, QC, G5L3A1, Canada. - C. N. Meynard, \\ INRA, UMR CBGP (INRA/IRD/Cirad/Montpellier SupAgro), Campus International de Baillarguet, CS 30016, FR-34988 Montferrier- \\ sur-Lez cedex, France. - V. Devictor and N. Mouquet, Inst. des Sciences de l'Evolution UMR 5554, Centre National de la Recherche \\ Scientifique, Univ. Montpellier 2, CC 065, Place Eugène Bataillon, FR-34095 Montpellier Cedex 05, France.
}

\begin{abstract}
Dispersal is a key process in metacommunity dynamics, allowing the maintenance of diversity in complex community networks. Geographic distance is usually used as a surrogate for connectivity implying that communities that are closely located are considered more prone to exchange individuals than distant communities. However, in some natural systems, organisms may be subjected to directional dispersal (air or water flows, particular landscape configuration), possibly leading close communities to be isolated from each other and distant communities to be connected. Using geographic distance as a proxy for realised connectivity may then yield misleading results regarding the role of dispersal in structuring communities in such systems. Here, we quantified the relative importance of flow connectivity, geographic distance, and environmental gradients to explain polychaete metacommunity structure along the coasts of the Gulf of Lions (northwest Mediterranean Sea). Flow connectivity was estimated by Lagrangian particle dispersal simulations. Our results revealed that this metacommunity is strongly structured by the environment at large spatial scales, and that both flow connectivity and geographic distance play an important role within homogeneous environments at smaller spatial scales. We thus strongly advocate for a wider use of connectivity measures, in addition to geographic distance, to study spatial patterns of biological diversity (e.g. distance decay) and to infer the processes behind these patterns at different spatial scales.
\end{abstract}

The concept of metacommunity, defined as a set of distinct communities connected by dispersal, has marked a turning point in community ecology in shifting the focus from biological interactions to a more complex vision including environmental filtering, dispersal or random effects (Leibold et al. 2004, Holyoak et al. 2005, Logue et al. 2011). While the initial metacommunity frameworks (i.e. neutrality, patch dynamics, species sorting, and mass effect) were intentionally oversimplified, they helped to build a more process-based large-scale ecology (Leibold et al. 2004, McGill 2010, Massol et al. 2011). For example, the neutral theory, which assumes ecological equivalence between species, has helped defining the role of dispersal and stochastic processes in structuring ecological communities (Bell 2001, Hubbell 2001, Chave 2004). Similarly, niche-based studies recognising ecological differences between species have emphasized the influence of environmental heterogeneity and patch extinction-colonisation dynamics (Tilman 1994, Mouquet and Loreau 2002). It is now accepted that communities are structured by a combination of these processes to different degrees (Hubbell 2001, Holyoak et al. 2005, Cavender-Bares et al. 2009). The potential of adopting a more integrated approach in which the relative influences of environmental gradients, dispersal, and biological interactions on different types of metacommunities are all quantified is now widely recognised (Logue et al. 2011). In other words, under the current metacommunity framework, these mechanisms are not exclusive, but rather complementary (Tuomisto et al. 2003, Cottenie 2005, Ellis et al. 2006, Meynard and Quinn 2008, Drakou et al. 2009, Zhang et al. 2010, Meynard et al. 2011). Therefore, rather than trying to define which is the single most important structuring force, the focus is now on understanding their relative importance, or what proportion of the overall variance in community structure can be explained by each process.

Among the patterns that have been used to explain community composition, community similarity ('beta diversity') has been widely documented (Cottenie 2005, Tuomisto and Ruokolainen 2006). In particular, the decrease in community similarity with geographic distance, the so-called 'distance decay', has proven to be common to different groups of organisms (Soininen et al. 2007): closely-located communities are generally more similar in terms of species composition than those located further apart (Tuomisto et al. 2003). This pattern is expected if 
dispersal is an important limiting factor in structuring ecological communities. However, spatial autocorrelation in biological data can also arise from environmental filtering: sites that are located at short distances are more likely to be environmentally similar and thus suitable for the same species (Legendre and Legendre 1998, Lichstein et al. 2002). These two different mechanisms (dispersal and environmental filtering) will therefore produce similar predictions regarding distance decay, and are therefore difficult to separate in empirical studies (Meynard et al. 2011).

It may nevertheless be possible to disentangle the relative roles of dispersal and environmental filtering in particular natural systems where each one of these produces different spatial structures. In many ecological systems, dispersal is likely to be influenced not only by geographic distance but also by its direction. For example, dispersal of seeds in some terrestrial plants (Minami and Azuma 2003) and dispersal of freshwater invertebrates in some aquatic systems (Vanschoenwinkel et al. 2009) are driven by winds, and larval dispersal of marine organisms is influenced by oceanic currents and, to some lesser extent, by larval behaviour (Cowen et al. 2007). In these systems, the directionality of dispersal influences connectivity between communities, which prevents the latter to be fully overlapping with environmental gradients. In such cases, comparing changes in community composition with geographic distance does not account for directional dispersal. Instead, a connectivity measure based on landscape properties (e.g. hydrodynamic, aerodynamic or vector-mediated processes) and the biology of the dispersing organisms should be more relevant to test the relative effects of dispersal and environmental filtering in shaping community structure and composition.

Marine environments are ideal systems in which to implement such analyses. In these systems, connectivity is an important determinant of marine community structure (Kinlan et al. 2005, Watson et al. 2010) and can limit population abundances (Bode et al. 2006, Guizien et al. 2006). Moreover, marine organisms are strongly influenced by asymmetric dispersal (i.e. where connectivity between communities $\mathrm{A}$ to $\mathrm{B}$ differs from connectivity between $\mathrm{B}$ to A, Salomon et al. 2010), and water flows in the ocean create highly complex structures, generating gyres favouring retention in some areas (Hill et al. 1996), or streams favouring long-distance routes (Botsford et al. 2003). In such complex systems, connectivity between communities will thus not be a simple linear, Gaussian or exponential function of geographic distance but, rather, will be influenced by the characteristics (e.g. speed, direction) of the medium transporting organisms (Sammarco and Andrews 1988, Cowen et al. 2000). Although the importance of local biotic and abiotic conditions in the maintenance of marine organisms has been demonstrated (Galeron et al. 2000, Gogina et al. 2010), quantifying the relative effects of realised flow connectivity (effective links between communities and their strengths) versus environmental filtering in the recruitment success of benthic organisms has rarely been achieved (Scheltema 1986, Roughgarden et al. 1988, Caley et al. 1996, Connolly and Roughgarden 1999).

Here, we account for both flow connectivity (hydrodynamically-driven exchange of individuals between different locations) and geographic distance (linear representation of connectivity) to better understand the spatial structure of a marine invertebrate metacommunity along the coastline of the northwest Mediterranean Sea. The data set used consists of 21 transects, perpendicular to the shore, along the coastline of the Gulf of Lions, where geostrophic currents display a typical directional windinduced regime (Millot 1990). We focused on the polychaetes, which are a highly diverse group, both taxonomically and functionally (McHugh and Fong 2002). In the Gulf of Lions, polychaetes make up a large part of the abundance and biomass of the benthos and are strongly structured along environmental gradients (Grémare et al. 1998, Labrune et al. 2007). A measure of connectivity that estimates larval dispersal based on ocean current simulations was used as an alternative and more realistic measure of dispersal than that predicted by geographic distance. Note that as we explicitly account for space and the environment, our statistical approach can be related to the variation partitioning strategy outlined and discussed against other approaches in Logue et al. (2011). We tested how much the environmental gradient was structuring community composition and how much of the remaining variation was explained by geographic distance and our measure of flow connectivity. We used the correlation between species turnover (beta diversity) and flow connectivity as an estimation of dispersal limitation in structuring the polychaete metacommunity at different spatial scales. If dispersal is dominant, and spatial autocorrelation is only reflecting dispersal limitations, we would expect beta diversity to be strongly correlated with flow connectivity. On the contrary, if environmental filtering is dominant, and spatial autocorrelation is reflecting environmental structure rather than dispersal limitations, we would expect communities to be strongly correlated with the environment.

\section{Methods}

\section{Study area}

The Gulf of Lions (Fig. 1) is located in the northwestern part of the Mediterranean Sea, between Cape Creus (Spain) and Cape Croisette (Marseille, France). It is characterised by a large continental shelf, up to $80 \mathrm{~km}$ wide at Cape Agde (France), with a mean depth of approximately $76 \mathrm{~m}$. At the boundary of the continental shelf, the shelf break is crossed by submarine canyons. Towards the continent, the local orography plays a key role on the main wind regimes: the Tramontane wind blows from north-northwest between the Pyrenees and the Massif Central (western side of the Gulf), and the Mistral wind blows from the north in the Rhône valley between the Massif Central and the Alps (eastern side of the Gulf). Since the Mediterranean Sea has a microtidal regime (tidal amplitudes lower than $0.5 \mathrm{~m}$ ), the coastal circulation mainly results from the interaction of these winds at regional scale, river inputs, and a large scale thermo-haline northern current flowing from east to west along the continental shelf break (Millot 1990, Estournel et al. 2003). 


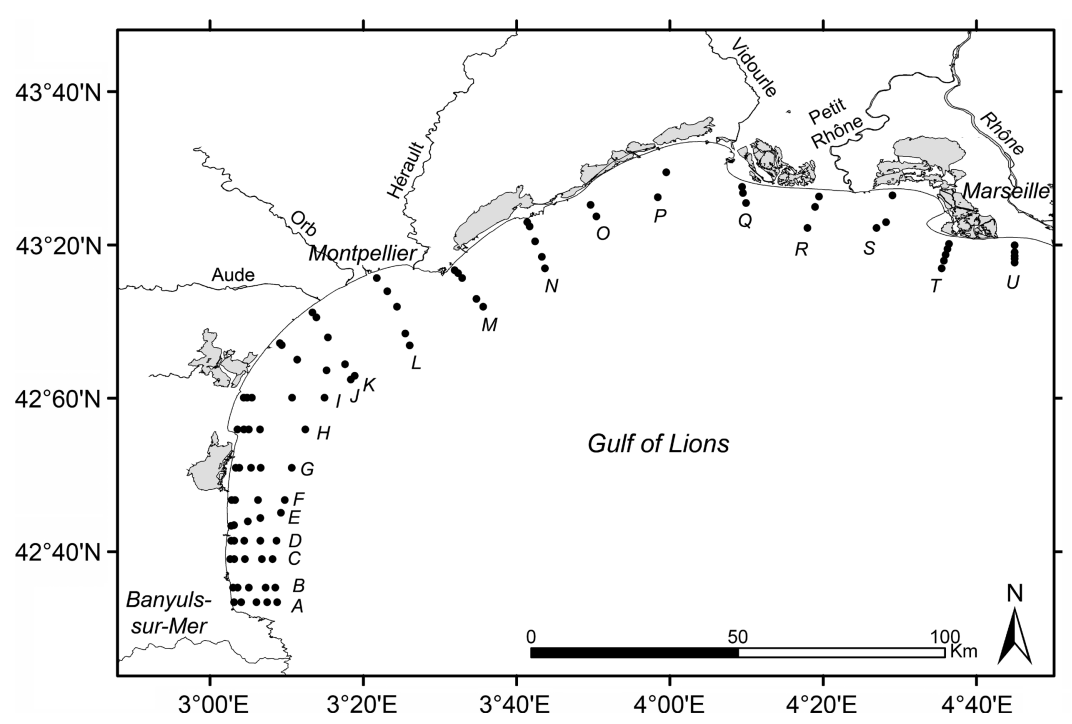

Figure 1. Location of the 92 sites sampled during the oceanographic campaign in 1998. Transects were located along the Gulf of Lions, between the French-Spanish border and the eastern part of the Rhône River. Stations were located between 10 and $50 \mathrm{~m}$ water depth. Adapted from Labrune et al. (2007).

\section{Polychaete survey and environmental data}

Between 19 and 29 September 1998, sampling was conducted in the Gulf of Lions along the portion of coast between the French-Spanish border and the mouth of the Rhône River to collect benthic samples from soft bottoms. This section of coast is approximately $110 \mathrm{~km}$ from south to north and $140 \mathrm{~km}$ from west to east (Fig. 1). Twenty-one cross-shore transects were sampled at two to five stations (five stations on 15 transects, four stations on one transect, three stations on three transects, two stations on two transects, 92 stations in total), with similar sampling protocol. At each station, four sediment samples were collected using a $0.1 \mathrm{~m}^{2}$ van Veen grab, from which three were taken for benthic macrofauna identification to the species level, and one for granulometric and organic content analysis. Macrofauna samples were immediately sieved with a $1 \mathrm{~mm}$ mesh and the fauna retained was fixed in 5\% formalin. Samples were then sorted at the laboratory to separate polychaetes from the remaining macrofauna. Identification of polychaete species was done as described in Labrune et al. (2007). Polychaetes were identified to the lowest practical taxonomic level and counted. Unidentified taxa were only counted when they could not be mistaken for other identified taxa and counted as separate species. Sediment granulometry analysis showed that the marine sea floor is composed of several sediment types stretching along the coast, ranging cross-shore from sandy to muddy sediments (Labrune et al. 2007).

\section{Spatial and environmental data analysis}

Geographic distance, flow connectivity, and environmental distance between each pair of stations were calculated. Geographic distance between each pair of stations was calculated using latitudinal and longitudinal WGS84 coordinates of each station. Transforming this linear geographic distance matrix to a Gaussian or exponential connectivity matrix was not performed here, contrary to other studies because it would intensify connectivity between close sites and reduce connectivity between distant sites, patterns that are already captured, more accurately, in the flow connectivity matrix. Flow connectivity was assessed using numerical simulations of larval dispersal in the Gulf of Lions including realistic hydrodynamic forcing of 2004. Hydrodynamic simulations (using the SYMPHONIE computer code: Johns et al. 1992, Marsaleix 1993, Estournel et al. 2003) have been validated in a number of studies in this area using in situ and satellite observations (e.g. Rhône river plume, Estournel et al. 1997, Marsaleix et al. 1998, Estournel et al. 2001; northern current inflow, Auclair et al. 2001; wind-induced currents, Estournel et al. 2003). Dispersal of virtual active larvae released from spawning points situated along the coasts of the Gulf of Lions was calculated using the Lagrangian procedure described in Guizien et al. (2006). Flow connectivity among the sampling stations was quantified by counting the number of virtual larvae coming from the spawning points and reaching areas delimited around the stations, between 5 and $50 \mathrm{~m}$ depth, after four weeks of dispersal (Supplementary material Appendix 1 and Fig. A1 for details).

An environmental Euclidian distance matrix was calculated between each pair of stations using field environmental measurements directly related to the sediment: depth, grain size (median particle diameter: d50), total carbon and nitrogen content in sediment, organic carbon in sediment, organic carbon to nitrogen ratio in the sediment. We also used other environmental variables, namely chlorophyll a (chl a) and sea surface temperature (SST), that are known to affect water column properties and thus indirectly sediment properties (e.g. through organic matter enrichment). Estimates of these two variables were derived from MODIS imagery (<http://modis.gsfc.nasa.gov/ $>$ ) as seasonal averages for 2006 . All these environmental variables were scaled to have a mean equal to 0 and a variance equal to 1 prior to distance calculation. 


\section{Estimating beta diversity}

Similarity between each pair of polychaete communities was assessed using the Simpson beta-diversity index calculated as $\beta_{\text {sim }}=\min (b, c) /(\min (b, c)+a)$, where $a$ represents the total number of species occurring in both communities, $b$ represents the total number of species that occur in the neighbouring community but not in the focal one, and $c$ represents the total number of species that occur in the focal community but not in the neighbouring one (Koleff et al. 2003). This index focuses on species turnover between sites while standardizing the effects of changes in species richness between these sites (Koleff et al. 2003). It is related to the Jaccard and Sorensen indices, but is less sensitive to sample size, and generally performs better than other beta diversity indices (Koleff et al. 2003, Baselga 2010). We used this index because of large differences in polychaete species richness among the communities sampled, with a few species (e.g. Ditrupa arietina) that largely dominated in some places. This index reaches a maximum when the proportion of species shared in two communities $(a)$ is small, and when the proportion of species gained and lost when moving from the focal $(b)$ to the neighbouring $(c)$ community is similar.

\section{Statistical analysis}

We assessed whether and how similarity in species composition among stations was related to environmental gradients, flow connectivity, and geographic distance. Significance of the Pearson product-moment correlations was computed using Mantel tests (Mantel 1967) and partial Mantel tests (Smouse et al. 1986) using the vegan library (Oksanen 2011) in the statistical package $R$ ver. 2.13.0 (R Development Core Team). These tests used a modified regression analysis between two (Mantel test) or three (partial Mantel tests) matrices. The rows and the columns of the matrices were randomly permuted 10000 times to calculate the correlation coefficient $r$. Finally, a Monte Carlo simulation method was used to estimate the statistical significance of each test. The Mantel tests were used to assess which component, among the environment, geographic distance and connectivity, was best correlated with beta diversity. The partial Mantel tests were complementary of the Mantel tests to further determine if the effects of one of the components were hidden behind the effects of another. For instance, if the environment is spatially autocorrelated, partialing out geographic distance in a Mantel test using the environment should remove significance of the environment.

\section{Scale of the analysis}

Depth can be an important factor determining benthic community structure (Garrabou et al. 2002, Wei et al. 2010). All Mantel and partial Mantel tests were thus performed for all stations, and separately for three groups of stations sampled at depths of 1) 10 and $20 \mathrm{~m}$, 2) $30 \mathrm{~m}$, and 3) 40 and $50 \mathrm{~m}$. This division corresponds roughly to sediment layout (bands of similar sediment types stretching along the coastline) and to the four clusters of polychaete assemblages previously defined in Labrune et al. (2007). These bands of stations are relatively homogeneous environmentally, particularly with respect to sediment and depth, allowing us to decouple the effects of environment and both connectivity and geographic distance while controlling for the influence of depth.

\section{Results}

Both environment and flow connectivity were spatially structured (Fig. 2). When all environmental properties were considered, environmental differences increased with geographic distance, i.e. closer sites were more similar between them than sites located far apart (Fig. 2A). This pattern was reinforced when stations of the same depth were considered (30 m Fig. 2B, and see Fig. A2 for other depths), i.e. environmental similarity among closely located sites was stronger when looking within a depth band. Mantel tests showed that connectivity was not significantly correlated with geographic distance (Table 1, Mantel test). We noted nonetheless a triangular relationship between connectivity and geographic distance (Fig. 2C-D). This reveals that 1) sites far away from each other have weaker chances to be connected, even if they are on the same pathway in terms of hydrodynamics, and that 2) exchange rates of closely located sites can vary from small to large values, likely because of hydrodynamics directionality. Retention (within-community connectivity) reached $4 \%$ and occurred for nearly every site during the elapsed time of four week-dispersal, which means that each local community is partly supported by self-recruitment (Fig. A1). Inter-community connectivity rates varied from 0 (absolutely no connectivity) to $3 \%$, and connectivity was greater below the retention diagonal than above, meaning that the flow was predominantly oriented along the coast from east to west (Supplementary material Appendix 1 Fig. A1). This pattern indicates that connectivity is unevenly distributed over the study area. Overall, flow connectivity and geographic distance provided complementary information about spatial structure of the metacommunity.

We found a hump-shaped relationship between species richness and depth $\left(\mathrm{p}\left(\mathrm{depth}^{2}\right)<0.001\right.$, Fig. 3A; see also Labrune et al. 2007), with species richness peaking at $30 \mathrm{~m}$ (Fig. 3A). Coarse sediments found in most 10 to $30 \mathrm{~m}$-depth stations also tended to host more individuals $\left(\mathrm{R}^{2}=0.17, \mathrm{p}<0.001\right.$, Fig. 3B). This abundance effect was driven by one dominant species, Ditrupa arietina, at these stations, but not by a change in the number of species present (Fig. 3C). As expected, depth and grain size were correlated $\left(R^{2}=0.37, p<0.001\right.$, Fig. $\left.3 D\right)$ : coarse (sandy) sediment dominated in shallow water, whereas the mud content of sediments increased with depth. The environmental gradient was therefore stronger when all stations (thus all depths) were included in the analysis, and weaker when each depth was considered separately, except around the mouth of the Rhône River, due to river particle deposits during flooding events (Marion et al. 2010) allowing muddy sediments to be mixed with sandy sediments at shallow depths (Labrune et al. 2007).

Mantel and partial Mantel tests of the relationships between environmental properties and connectivity and 

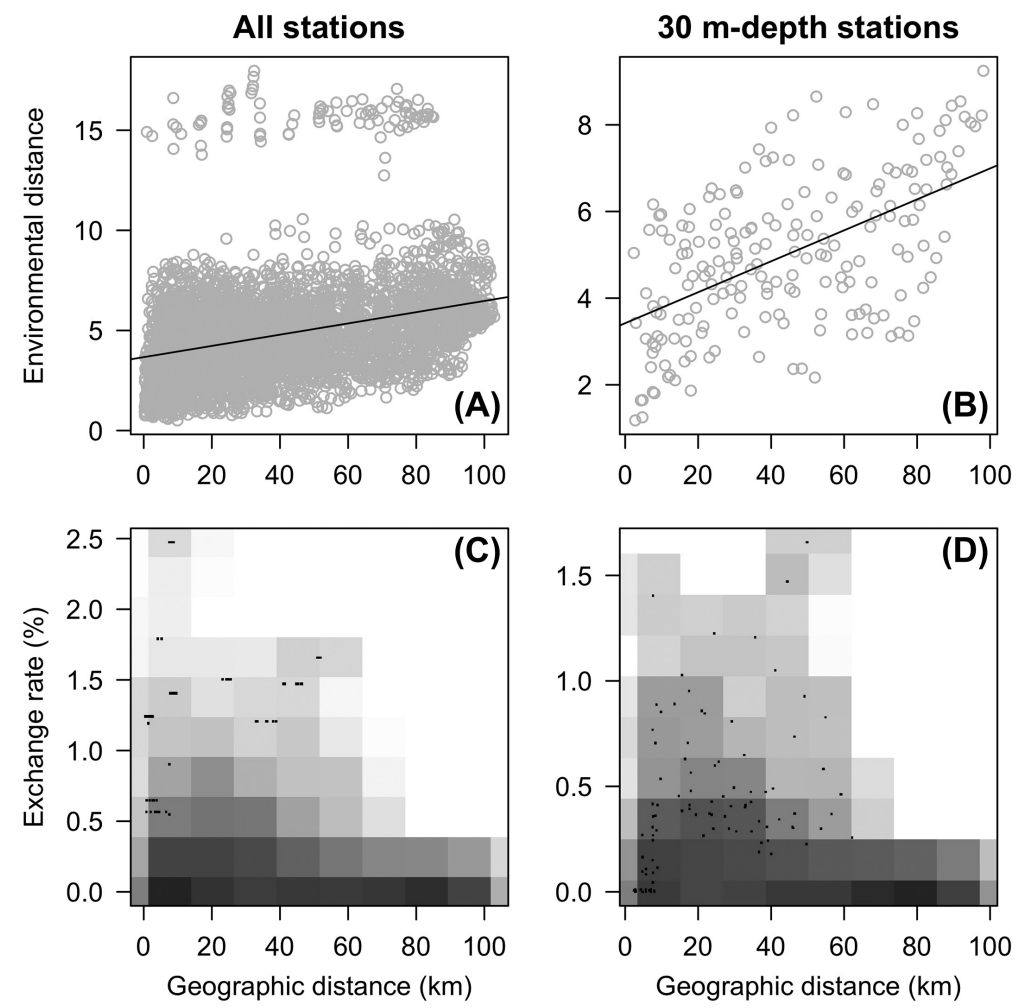

Figure 2. Relationships between geographic distance and environmental distance $(A): R^{2}=0.11, p<0.001 ;(B): R^{2}=0.30, p<0.001$ and flow connectivity measured as exchange rates $(\mathrm{C}, \mathrm{D})$ for all stations and for stations located at $30 \mathrm{~m}$-depth. The shading of each square is proportional to the density of dots in that square.
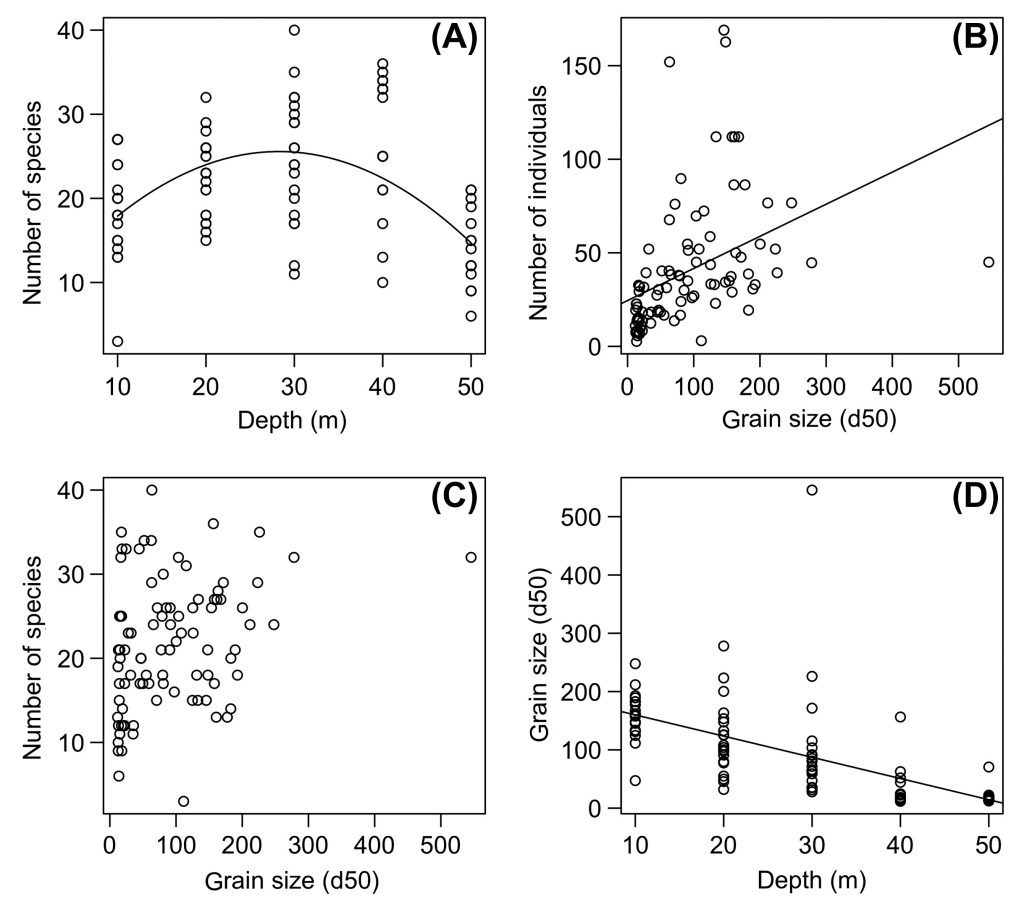

Figure 3. Relationships between environmental and community characteristics (number of individuals and number of species, A, B, C) and between the main environmental characteristics (grain size and depth, D). Hump-shaped correlation was found between depth and number of species $(\mathrm{A})$ : polynomial model with richness $=-0.023 \times$ depth $^{2}+1.3 \times$ depth +7.29 , $\mathrm{p}\left(\right.$ depth $\left.{ }^{2}\right)<0.001$; significant linear correlations were found between grain size and number of individuals $(B): R^{2}=0.17, p<0.001$ and depth $(D): R^{2}=0.37, p<0.001$; no significant correlation was found between grain size and the number of species $(\mathrm{C})$. 
Table 1. Correlations of species distance with environment, geographic distance, and connectivity, and correlation of geographic distance with connectivity, for all sites (92) and 30 m-deep sites measured using Mantel and partial Mantel tests. The tests were based on Pearson's product-moment correlation (10000 permutations) for species distance matrix against matrices of environmental distance, geographic distance, and connectivity.

\begin{tabular}{|c|c|c|c|c|c|}
\hline \multirow{2}{*}{$\begin{array}{l}\text { Mantel } \\
\text { Simpson beta diversity vs }\end{array}$} & \multicolumn{2}{|c|}{$r(p$ value $)$} & \multirow{2}{*}{$\begin{array}{c}\text { Partial Mantel } \\
\text { Simpson beta diversity vs }\end{array}$} & \multicolumn{2}{|c|}{$r(p$ value $)$} \\
\hline & all & $30 \mathrm{~m}$ & & all & $30 \mathrm{~m}$ \\
\hline Environment & $0.328(<0.001)$ & $0.254(0.013)$ & $\begin{array}{l}\text { Environment | geographic } \\
\text { distance }\end{array}$ & $0.34(<0.001)$ & $0.067(0.274)$ \\
\hline Geographic distance & $0.023(0.14)$ & $0.367(<0.001)$ & Environment | connectivity & $0.329(<0.001)$ & $0.292(0.004)$ \\
\hline Connectivity & $0.005(0.428)$ & $0.192(0.023)$ & $\begin{array}{l}\text { Geographic distance } \\
\text { environment }\end{array}$ & -0.098 & $0.282(0.002)$ \\
\hline $\begin{array}{l}\text { Geographic distance vs } \\
\text { connectivity }\end{array}$ & $-0.333(1)$ & $-0.383(1)$ & Connectivity | environment & $0.029(0.101)$ & $0.242(0.006)$ \\
\hline
\end{tabular}

geographic distance revealed the complexity of the spatial organisation of these communities. When all stations were considered, beta diversity was significantly correlated with environmental variations (Table 1, Mantel test). This was confirmed by partial Mantel tests which revealed that, when geographic distance or flow connectivity were taken into account, beta diversity was still significantly correlated to the environment (Table 1, partial Mantel tests). Conversely, when the environment was taken into account, beta diversity was neither significantly correlated with geographic distance nor with flow connectivity (Table 1). This suggests that, at least at this scale, the environment was the most important driver of community composition. When the same analysis was performed within depth bands, results showed that the environment, geographic distance and flow connectivity were all significantly correlated with beta diversity (Table 1 and Fig. 4 for $30 \mathrm{~m}$ depth; other depth analyses can be found in the Supplementary material Appendix 1 Table A1 and Fig. A3). When the environment was controlled for in the partial Mantel tests (Table 1), both geographic distance and flow connectivity remained significantly correlated with beta diversity. When geographic distance was partialed out, the environment was no longer correlated with beta diversity. On the contrary, when flow connectivity was partialed out, the environment remained significantly correlated to beta diversity. This suggests that the effect of the environmental filtering on species turnover depends on its spatial structure (e.g. the environment is strongly interrelated to geographic distance), but is independent of connectivity.

\section{Discussion}

This study provides an example of how the spatial structure of environmental variability can be partially decoupled from connectivity when studying their effects on community composition in dispersive environments. The patterns of spatial structure and connectivity, both when all sites are considered together and when depth bands are separated, reveal an important role of environmental gradients in shaping polychaete communities. Geographic distance per se and flow connectivity appear to be important drivers determining the composition of these communities when patterns of diversity are considered within depth bands, i.e. within more homogeneous environments.
A first important result is that the spatial scale considered influences the most relevant factors determining community structure. We found that alongshore flow connectivity was important when environmental heterogeneity was low, i.e. within depth bands, but that cross-shore environmental gradients were preponderant over connectivity when including all depth bands. This predominant role of the environmental filtering on polychaetes, previously highlighted in empirical studies from Labrune et al. (2007, 2008), suggests that community composition arises partly from species sorting (Holyoak et al. 2005). In marine environments, depth and associated characteristics such as sediment layout and grain size are believed to strongly influence the composition of benthic communities (Garrabou et al. 2002, Labrune et al. 2007, 2008), setting distinct niches for the organisms, hence driving dissimilarities between communities.

Nevertheless, and consistent with our results, recent theoretical and empirical studies have demonstrated that dispersal is also a significant process whose strength can strongly impact community structure (Mouquet et al. 2004, Cadotte and Fukami 2005, Venail et al. 2008). For instance, the laboratory experimental study carried out by Venail et al. (2008) highlighted that different levels of dispersal could induce changes of diversity in a bacterial metacommunity, and Cadotte and Fukami (2005) found that community structure changed over time and space when dispersal occurred at different spatial scales. In our study area, the decoupled effect of environment and flow connectivity on polychaete community structure may be due to the specific ocean current regime occurring in the area, which is partly uncorrelated with environmental patterns (sediment layout especially). Two nearby sites (i.e. in the same transect perpendicular to the coast, at different depths) may not be strongly connected when the water flow is parallel to the coast (Guizien et al. 2006), although some of them may be similar in terms of their physical properties (e.g. granulometry, Labrune et al. 2007). Exceptions may be encountered in specific areas such as towards the middle of the Gulf, where gyres and cross-shore connectivity may occur, allowing stronger connectivity between sites at different depths in this region.

This decoupling between environmental variability and connectivity is also consistent with empirical results in other systems. For example, Laliberté et al. (2009) found that the abundance of tree seedlings was first controlled by a 

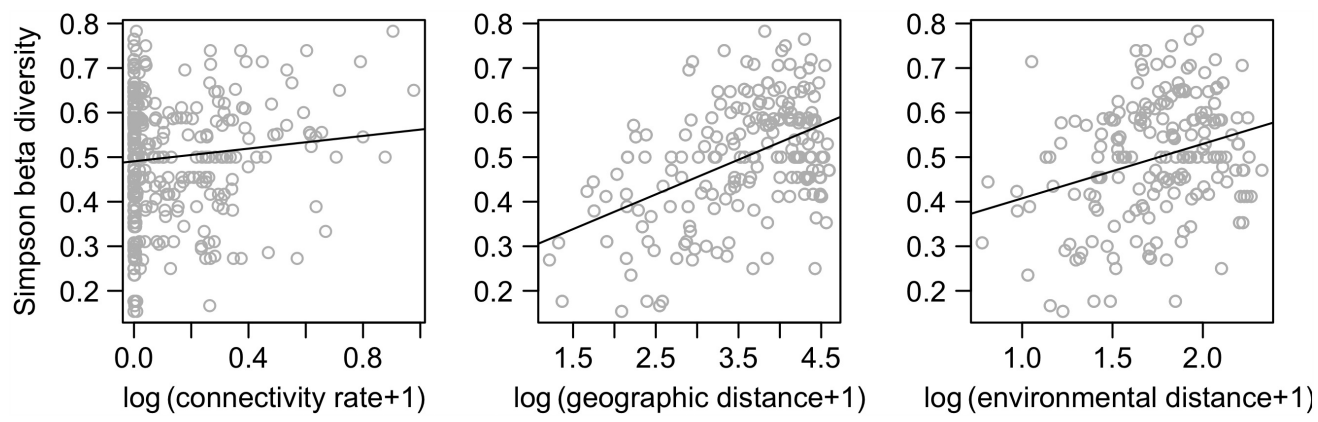

Figure 4. Relationships between beta diversity and flow connectivity, geographic and environmental distances for $30 \mathrm{~m}$-depth sites. Logarithm added of one for exchange rate (in percent), geographic distance (in $\mathrm{km}$ ) and Euclidian environmental distance is given.

broad environmental gradient, and then, within this gradient, by other spatial processes such as dispersal occurring at smaller scales. Another theoretical study pointed out that different levels of dispersal and regional environmental heterogeneity combined could affect community structure (Mouquet et al. 2006). Overall, our results provide empirical support for considering that metacommunity structure results from a combination of several mechanisms interacting at different spatial scales (Cadotte and Fukami 2005, Logue et al. 2011): environmental filtering predominating large scales, and dispersal being more important within similar environments. The possible existence of decoupling between spatial autocorrelation, environmental heterogeneity and connectivity needs to be further integrated using linear (e.g. this study) and non-linear methods to assess whether community structure, spatial structure, and connectivity interact non-linearly (Bode et al. 2011).

Patterns of similarity decay with geographic distance are not sufficient to study the influence of dispersal on metacommunity structure or dynamics since they can be linked to each asset of connectivity, environmental similarity and geographic distance. Decay of similarity is often examined using geographic distance (Soininen et al. 2007), as in our analysis, but it has also been found with other distance measures (e.g. environmental distance, Tuomisto et al. 2003; stream distance, Maloney and Munguia 2011). In the Gulf of Lions, we observed that environmental distance increased with geographic distance, so we used this environmental distance to perform tests on community similarity matrices, and found a decay of polychaete community similarity with increasing environmental distance. Other studies support this idea (Tuomisto et al. 2003, Duque et al. 2009, Maloney and Munguia 2011). For instance, Tuomisto et al. 2003 found an increase in environmental distance with geographic distance and a decay of similarity both with geographic and environmental distances. A recent study of Maloney and Munguia (2011) also reported different rates of decay with both environmental and geographic distances, suggesting that global decay patterns can emerge from a combination of different factors. These authors also found different rates of decay for the different regions they considered. Our analyses provide similar results, i.e. decay rates varied when different depth bands were considered. This decay within specific subscales demonstrates that complex community dynamics need to be investigated not only at large regional scale but also within specific environments to account for structural factors of community composition. To refine the results, analysis including more specific sediment types within depth bands could be conducted, especially in the region of the mouth of the Rhône River which displays a complex sediment layout and where mud is found at shallower depths than in the rest of the Gulf.

Beyond the particular marine system studied, dispersal of propagules also occurs for terrestrial organisms, either through vectors (e.g. vertebrates transporting seeds: Howe and Smallwood 1982) or trough atmospheric (seeds transported by wind: Nathan et al. 2011) and oceanographic processes (seed water-dispersal in coastal areas: Brunbjerg et al. 2012). On land, some of these processes might be directional, but may probably be more variable due to smaller inertia in air than in water (Gaylord et al. 2006) and to the vectors' behaviour (e.g. plants: Ozinga et al. 2004). In marine ecosystems, dispersal resulting in connectivity between regions can play a major role on community dynamics because it enables the colonisation of distant areas by marine species and favours their mixing at large scales (Caley et al. 1996, Bode et al. 2006, Guizien et al. 2006). However, the exact role of connectivity vs environmental gradients or local environments leading to recruitment success remains difficult to assess because of a temporal decoupling of these two factors: larvae are transported by currents and settle when competent, and only after that their chances of developing into adults will depend on the environmental conditions found on their settling site (Butman 1987). Conversely, currents, if too strong, may prevent some organisms from being transported to a suitable habitat or settlement site (Guizien et al. 2006).

Our study illustrates the importance of another potential caveat concerning connectivity issues in marine environments, which is the lack of accurate estimate of flow connectivity itself. Indeed, empirical studies trying to measure connectivity have only been conducted at small or large spatial scales, for particular species and with specific methods (Incze et al. 2000, Carson et al. 2011, Saenz-Agudelo et al. 2011), but no synthetic connectivity index exists to date. Numerical simulations applied to different areas of the globe have allowed approximations of connectivity patterns for local populations (James et al. 2002, Bode et al. 2006, Marinone et al. 2008, Ayata et al. 2010), but constructing accurate hydrodynamic models coupled to particle dispersal is demanding in terms of their design, 
parameterisation, and computer resources needed to run them, especially when designed at fine resolution or close to the coast where fine-scale physical processes occur. Here, connectivity was determined using a realistic 3D hydrodynamical model with a simulation resolution and coverage adapted to study dispersal at large scale (Guizien et al. 2006). Because the coupling with a species-specific larval behaviour may not account for the different behaviours and pelagic larval duration (PLD) of all the polychaete species present in the Gulf, we calculated exchange rates using a four-week PLD, which is a good estimate of mean PLD for benthic invertebrates (McEdward 1995). Subsequently incorporating different types of larvae in the model (active, passive, and with different PLD) was not possible in our simulations, but attempts to do so were achieved in Guizien et al. (2012). The difficulty to account for these discrepancies lies in calculating a final connectivity matrix that incorporates appropriate proportions of all larval species, which first implies running separate simulations, species by species. Only this could lead to more realistic estimations of flow connectivity, and consequently, of connectivity effects on metacommunity structure. This could at the same time allow assessing the importance of connectivity on particular species of interest (Treml et al. 2012). Another limitation might come from having used a flow connectivity matrix estimated for 2004 and a one-year regional diversity survey in 1998: coastal circulation and diversity temporal variability may partly blur the correlation between the average connectivity matrix and the diversity survey, even if inter-annual variability of the average connectivity matrix can be ignored. Moreover, the single year diversity survey may have been partly biased by peculiar connectivity in the years before diversity assessment for short-lived species. It would therefore be beneficial to gather connectivity matrices for different years, especially around the year of diversity surveys.

Metacommunities are structured by a number of processes, in particular by environmental and dispersal filters (Leibold et al. 2004, Holyoak et al. 2005), which ecologists have mostly studied as separate paradigms (Logue et al. 2011). Here, by using a measure of connectivity decoupled from geographic distance, we have shown than these paradigms may be spatially interlocked, leading to a more comprehensive understanding of metacommunity dynamics in this region and allowing to sort out the importance and scale of action of environmental and dispersal processes. Incorporation of connectivity estimates in the analysis, a characteristic that few studies have done to date, rendered the study more realistic concerning the processes occurring in dispersive environments. Environmental properties that were used in this study are known to influence polychaete communities (Arvanitidis et al. 2002, Labrune et al. 2007), but other variables may be taken into account in further analysis (e.g. oxygen, phosphate and silicate). Further work and other methods should be implemented to capture more precisely the effects of dispersal only on community structure, and assess in which type of marine ecosystem dispersal is a critical process. The approach presented here could also be applied to other freshwater and terrestrial ecosystems in which connectivity is known, and displaying complex or unusual dispersal patterns (e.g. asymmetric, oriented, gyres), and to other organisms dispersing particles (e.g. seeds for plants). Our results may also be useful for diversity conservation since the design of marine protected areas and terrestrial natural reserves requires a sound understanding of community dynamics, its dispersal patterns and its interaction with habitats to protect, at both local and regional scales (Economo 2011). New analyses will be needed to meet these requirements, including elements of mechanistic landscape ecology and statistical analysis of biogeographic patterns within the same framework.

Acknowledgements - This work was partly supported by the French Ministère de l'Enseignement supérieur et de la Recherche through a doctoral grant. VD received funding from the Fondation pour la Recherche sur la Biodiversité (FRB, research projects FABIO and PHYBIO). We thank Antoine Grémare (EPOCOASU, Arcachon, France), François Charles and Jean-Michel Amouroux (LECOB, Banyuls-sur-mer, France), Joao Gil and Rafael Sarda (CEAB, Blanes, Spain) who have organised and realised data collection, identification and database design. We are grateful to members of POC (Toulouse, France) for providing the ocean model SYMPHONIE. Finally, we thank Julian Caley and Camille Mellin for helpful advice and comments on the manuscript.

\section{References}

Arvanitidis, C. et al. 2002. Seascape biodiversity patterns along the Mediterranean and the Black Sea: lessons from the biogeography of benthic polychaetes. - Mar. Ecol. Prog. Ser. 244: 139-152.

Auclair, F. et al. 2001. The penetration of the Northern Current over the Gulf of Lions (Mediterranean) as a downscaling problem. - Oceanol. Acta 24: 529-544.

Ayata, S. D. et al. 2010. How does the connectivity between populations mediate range limits of marine invertebrates? A case study of larval dispersal between the Bay of Biscay and the English Channel (northeast Atlantic). - Prog. Oceanogr. 87: $18-36$.

Baselga, A. 2010. Partitioning the turnover and nestedness components of beta diversity. - Global Ecol. Biogeogr. 19: $134-143$.

Bell, G. 2001. Neutral macroecology. - Science 293: 2413-2418.

Bode, M. et al. 2006. Larval dispersal reveals regional sources and sinks in the Great Barrier Reef. - Mar. Ecol. Prog. Ser. 308: $17-25$.

Bode, M. et al. 2011. Different dispersal abilities allow reef fish to coexist. - Proc. Natl Acad. Sci. USA 108: 16317-16321.

Botsford, L. W. et al. 2003. Principles for the design of marine reserves. - Ecol. Appl. 13: S25-S31.

Brunbjerg, A. K. et al. 2012. Species sorting dominates plant metacommunity structure in coastal dunes. - Acta Oecol. 39: 33-42.

Butman, C. A. 1987. Larval settlement of soft-sediment invertebrates: the spatial scale of pattern explained by active habitat selection and the emerging role of hydrodynamical processes. - Oceanogr. Mar. Biol. 25: 113-165.

Cadotte, M. W. and Fukami, T. 2005. Dispersal, spatial scale, and species diversity in a hierarchically structured experimental landscape. - Ecol. Lett. 8: 548-557.

Caley, M. J. et al. 1996. Recruitment and the local dynamics of open marine populations. - Annu. Rev. Ecol. Syst. 27: 477-500.

Carson, H. S. et al. 2011. Evaluating the importance of demographic connectivity in a marine metapopulation. - Ecology 92: 1972-1984. 
Cavender-Bares, J. et al. 2009. The merging of community ecology and phylogenetic biology. - Ecol. Lett. 12: 639-715.

Chave, J. 2004. Neutral theory and community ecology. - Ecol. Lett. 7: 241-253.

Connolly, S. R. and Roughgarden, J. 1999. Theory of marine communities: competition, predation, and recruitment-dependant interaction strength. - Ecol. Monogr. 69: 277-296.

Cottenie, K. 2005. Integrating environmental and spatial processes in ecological community dynamics. - Ecol. Lett. 8: 1175-1182.

Cowen, R. K. et al. 2000. Connectivity of marine populations: open or closed? - Science 287: 857-859.

Cowen, R. K. et al. 2007. Population connectivity in marine systems: an overview. - Oceanography 20: 14-21.

Drakou, E. G. et al. 2009. Freshwater fish community structured more by dispersal limitation than by environmental heterogeneity. - Ecol. Freshwater Fish 18: 369-379.

Duque, A. et al. 2009. Distance decay of tree species similarity in protected areas on Terra Firme forests in Colombian Amazonia. - Biotropica 41: 599-607.

Economo, E. P. 2011. Biodiversity conservation in metacommunity networks: linking pattern and persistence. - Am. Nat. 177: E167-E180.

Ellis, A. M. et al. 2006. Evaluating the long-term metacommunity dynamics of tree hole mosquitoes. - Ecology 87: 2582-2590.

Estournel, C. et al. 1997. The plume of the Rhône: numerical simulation and remote sensing. - Continental Shelf Res. 17: 899-924.

Estournel, C. et al. 2001. The Rhône River plume in unsteady conditions: numerical and experimental results. - Estuar. Coast. Shelf Sci. 53: 25-38.

Estournel, C. et al. 2003. Observation and modeling of the winter coastal oceanic circulation in the Gulf of Lions under wind conditions influenced by continental orography (FETCH experiment). - J. Geophys. Res. 108 (C3).

Galeron, J. et al. 2000. Variation in structure and biomass of the benthic communities at three contrasting sites in the tropical northeast Atlantic. - Mar. Ecol. Prog. Ser. 197: 121-137.

Garrabou, J. et al. 2002. Structure and dynamics of north-western Mediterranean rocky benthic communities along a depth gradient. - Estuar. Coast. Shelf Sci. 55: 493-508.

Gaylord, B. et al. 2006. Macroalgal spore dispersal in coastal environments: mechanistic insights revealed by theory and experiment. - Ecol. Monogr. 76: 481-502.

Gogina, M. et al. 2010. Distribution of benthic macrofaunal communities in the western Baltic Sea with regard to near-bottom environmental parameters. 2. Modelling and predictions. - J. Mar. Syst. 80: 57-70.

Grémare, A. et al. 1998. Long-term comparison of macrobenthos within the soft bottoms of the Bay of Banyuls-sur-mer (northwestern Mediterranean Sea). - J. Sea Res. 40: 281-302.

Guizien, K. et al. 2006. Dispersal of Owenia fusiformis larvae by wind-driven currents: turbulence, swimming behaviour and mortality in a three-dimensional stochastic model. - Mar. Ecol. Prog. Ser. 311: 47-66.

Guizien, K. et al. 2012. Using realistic Lagrangian larval dispersal simulations for marine protected area design: application to the Gulf of Lions (northwest Mediterranean). - Limnol. Oceanogr. 57: 1099-1112.

Hill, A. E. et al. 1996. The western Irish Sea gyre: a retention system for Norway lobster (Nephrops norvegicus)? - Oceanol. Acta 19: 357-368.

Holyoak, M. et al. 2005. Metacommunities: a framework for large-scale community ecology. - In: Holyoak, M. et al. (eds), Metacommunities, spatial dynamics and ecological communities. Univ. of Chicago Press, pp. 1-31.
Howe, H. F. and Smallwood, J. 1982. Ecology of seed dispersal. - Annu. Rev. Ecol. Syst. 13: 201-228.

Hubbell, S. P. 2001. The unified neutral theory of biodiversity and biogeography. - Princeton Univ. Press.

Incze, L. S. et al. 2000. Neustonic postlarval American lobsters, Homarus americanus, in the western Gulf of Maine: spatial and interannual variations. - Can. J. Fish. Aquat. Sci. 57: $755-765$.

James, M. K. et al. 2002. The structure of reef fish metapopulations: modelling larval dispersal and retention patterns. - Proc. R. Soc. B 269: 2079-2086.

Johns, B. et al. 1992. On the wind-driven coastal upwelling in the Gulf of Lions. - J. Mar. Syst. 3: 309-320.

Kinlan, B. P. et al. 2005. Propagule dispersal and the scales of marine community process. - Divers. Distrib. 11: 139-148.

Koleff, P. et al. 2003. Measuring beta diversity for presence-absence data. - J. Anim. Ecol. 72: 367-382.

Labrune, C. et al. 2007. Assessment of soft-bottom polychaete assemblages in the Gulf of Lions (NW Mediterranean) based on a mesoscale survey. - Estuar. Coast. Shelf Sci. 71: $133-147$.

Labrune, C. et al. 2008. Structure and diversity of shallow soft-bottom benthic macrofauna in the Gulf of Lions (NW Mediterranean). - Helgoland Mar. Res. 62: 201-214.

Laliberté, E. et al. 2009. Assessing the scale-specific importance of niches and other spatial processes on beta-diversity: a case study from a temperate forest. - Oecologia 159: 377-388.

Legendre, P. and Legendre, L. 1998. Numerical ecology, 2nd English edn. - Elsevier.

Leibold, M. A. et al. 2004. The metacommunity concept: a framework for a multi-scale community ecology. - Ecol. Lett. 7: 601-613.

Lichstein, J. W. et al. 2002. Spatial autocorrelation and autoregressive models in ecology. - Ecol. Monogr. 72: 445-463.

Logue, J. B. et al. 2011. Empirical approaches to metacommunities - a review and comparison to theory. - Trends Ecol. Evol. 26: 482-491.

Maloney, K. O. and Munguia, P. 2011. Distance decay of similarity in temperate aquatic communities: effects of environmental transition zones, distance measures and life histories. - Ecography 34: 287-295.

Mantel, N. 1967. Detection of disease clustering and a generalized regression approach. - Cancer Res. 27: 209-220.

Marinone, S. G. et al. 2008. Connectivity in the northern Gulf of California from particle tracking in a three-dimensional numerical model. - J. Mar. Syst. 71: 149-158.

Marion, C. et al. 2010. In situ record of sedimentary processes near the Rhône River mouth during winter events (Gulf of Lions, Mediterranean Sea). - Continental Shelf Res. 30: 1095-1107.

Marsaleix, P. 1993. Modélisation tridimensionnelle de la circulation océanique dans le Golfe du Lion. - PhD thesis, Univ. Paul Sabatier de Toulouse.

Marsaleix, P. et al. 1998. A numerical study of the formation of the Rhône River plume. - J. Mar. Syst. 14: 99-115.

Massol, F. et al. 2011. Linking community and ecosystem dynamics through spatial ecology. - Ecol. Lett. 14: 313-323.

McEdward, L. 1995. Ecology of marine invertebrate larvae. - CRC Press.

McGill, B. 2010. Towards a unification of unified theories of biodiversity. - Ecol. Lett. 13: 627-642.

McHugh, D. and Fong, P. P. 2002. Do life history traits account for diversity of polychaete annelids? - Invertebr. Biol. 121: 325-338.

Meynard, C. N. and Quinn, J. F. 2008. Bird metacommunities in temperate South American forest: vegetation structure, area and climate effects. - Ecology 89: 981-990. 
Meynard, C. N. et al. 2011. Beyond taxonomic diversity patterns: how do $\alpha, \beta$ and $\gamma$ components of bird functional and phylogenetic diversity respond to environmental gradients across France? - Global Ecol. Biogeogr. 20: 893-903.

Millot, C. 1990. The Gulf of Lions' hydrodynamics. - Continental Shelf Res. 10: 885-894.

Minami, S. and Azuma, A. 2003. Various flying modes of wind-dispersal seeds. - J. Theor. Biol. 225: 1-14.

Mouquet, N. and Loreau, M. 2002. Coexistence in metacommunities: the regional similarity hypothesis. - Am. Nat. 159: 420-426.

Mouquet, N. et al. 2004. Immigration and local competition in herbaceous plant communities: a three-year seed-sowing experiment. - Oikos 104: 77-90.

Mouquet, N. et al. 2006. Consequences of varying regional heterogeneity in source-sink metacommunities: a mechanistic model. - Oikos 113: 481-488.

Nathan, R. et al. 2011. Mechanistic models of seed dispersal by wind. - Theor. Ecol. 4: 113-132.

Oksanen, J. 2011. vegan: community ecology package. R package ver. 1.17-10. (< http://CRAN-R-project.org/ package $=$ vegan $>$ ).

Ozinga, W. A. et al. 2004. Dispersal potential in plant communities depends on environmental conditions. - J. Ecol. 92: 767-777.

Roughgarden, J. et al. 1988. Recruitment dynamics in complex life cycles. - Science 241: 1460-1466.

Saenz-Agudelo, P. et al. 2011. Connectivity dominates larval replenishment in a coastal reef fish metapopulation. - Proc. R. Soc. B 278: 2954-2961.

Salomon, Y. et al. 2010. Effects of asymmetric dispersal on the coexistence of competing species. - Ecol. Lett. 13: 432-441.

Sammarco, P. W. and Andrews, J. C. 1988. Localized dispersal and recruitment in Great Barrier Reef corals: the Helix experiment. - Science 239: 1422-1424.

Supplementary material (Appendix oik-00377 at <www. oikosoffice.lu.se/appendix $>$ ). Appendix 1 .
Scheltema, R. S. 1986. On dispersal and planktonic larvae of benthic invertebrates: an eclectic overview and summary of problems. - Bull. Mar. Sci. 39: 290-322.

Smouse, P. E. et al. 1986. Multiple regression and correlation extensions of the Mantel test of matrix correspondence. - Syst. Zool. 35: 627-632.

Soininen, J. et al. 2007. The distance decay of similarity in ecological communities. - Ecography 30: 3-12.

Tilman, D. 1994. Competition and biodiversity in spatially structured habitats. - Ecology 75: 2-16.

Treml, E. A. et al. 2012. Reproductive output and duration of the pelagic larval stage determine seascape-wide connectivity of marine populations. - Integr. Compar. Biol. 52: $525-537$.

Tuomisto, H. and Ruokolainen, K. 2006. Analyzing or explaining beta diversity? Understanding the targets of different methods of analysis. - Ecology 87: 2697-2708.

Tuomisto, H. et al. 2003. Dispersal, environment and floristic variation of western Amazonian forests. - Science 299: 241-244.

Vanschoenwinkel, B. et al. 2009. Wind mediated dispersal of freshwater invertebrates in a rock pool metacommunity: differences in dispersal capacities and modes. - Hydrobiologia 635: 363-372.

Venail, P. A. et al. 2008. Diversity and productivity peak at intermediate dispersal rate in evolving metacommunities. - Nature 452: 210-214.

Watson, J. R. et al. 2010. Realized and potential larval connectivity in the southern California Bight. - Mar. Ecol. Prog. Ser. 401: 31-48.

Wei, C.-L. et al. 2010. Global patterns and predictions of seafloor biomass using random forests. - PLOS ONE 5: e15323. doi: 10.1371/journal.pone.0015323.

Zhang, C. et al. 2010. Partitioning temperate plant community structure at different scales. - Acta Oecol. 36: 306-313. 